\title{
Consumidores de Baixa Renda: Uma Revisão dos Achados de Estudos Feitos no Brasil
}

\section{Low Income Consumers: a Review of Brazilian Studies}

\author{
Marie Agnes Chauvel ${ }^{1}$ \\ Marina Pinto de Abreu Zornoff de Mattos ${ }^{2}$
}

\begin{abstract}
Resumo
As familias de classe C, D e E (Critério Econômico Brasil) representam, aproximadamente, três quartos da população brasileira. Na década de 1990, esses consumidores começaram a despertar a atenção das empresas e dos estudiosos da área de marketing. Ainda assim, existem, até o momento, poucos estudos acadêmicos sobre esse tema. Este artigo se propõe efetuar uma revisão desses trabalhos, de cunho essencialmente descritivo e interpretativo, confrontando e discutindo seus achados dentro de uma perspectiva interpretativa. Seu objetivo é o de tentar avançar na interpretação dos resultados dessas pesquisas, buscando, assim, contribuir para a construção de novos estudos. 0 artigo está estruturado em torno dos temas abordados nos estudos analisados: classe social; gestão do orçamento; experiência da compra; e papel do preço e da marca nas decisões de compra. Traz, como conclusão, uma proposta de articulação dos elementos interpretativos encontrados nas pesquisas analisadas. Resumidamente, duas racionalidades parecem coexistir na formação das decisões de consumo: uma, "dura", material, derivada da escassez de recursos, que impõe uma racionalização estrita dos gastos; outra, de ordem simbólica, ancorada em elementos culturais e particularmente, nas dimensões relacionais e hierárquicas da sociedade brasileira, bem como em instituições de forte significado nessa sociedade, como a familia e a religião.
\end{abstract}

Palavras-chave: consumidor de baixa renda; comportamento do consumidor.

\begin{abstract}
Low income consumers are today responsible for about 75\% of consumption in Brazil. In the mid 1990s, enterprises and scholars started to show interest for these consumers, which were neglected during prior decades. However there are still few academic studies on this topic and most of them are of an exploratory nature. The objective of this paper is to review the findings of these studies, confronting and discussing such findings from an interpretive point of view. The aim is to make headway in interpreting the results of the research, thus contributing to the construction of new studies. The paper was organized around the topics discussed in the reviewed studies: social class; management of the budget; the purchase experience and the role of prices and brands in purchase decisions. Results bring interpretive propositions, seeking to contribute for the construction of new studies. They suggest that two rationalities coexist in the decision-making process of household consumption. A "hard" material one, derived from scarcity of resources that imposes thrift and strict rationalization of expenditures and a symbolic one, anchored in cultural elements and especially in the relational and hierarchical dimensions of the Brazilian society, as well as in institutions with a strong purport in this society, such as family and religion.
\end{abstract}

Keywords: Low income consumers; Consumer behavior

\footnotetext{
${ }^{1}$ Doutora em Administração pelo Instituto pós-graduação pesquisa Administração da Universidade Federal do Rio de Janeiro - COPPEAD/UFRJ. Professora da Escola de Negócios da Pontifícia Universidade Católica do Rio de Janeiro - IAG/PUC-RJ Endereço: Rua Cupertino Durão, 147 Apto. 307 - Leblon - Rio de Janeiro/RJ - Brasil -CEP: 22441030 - Email: marie@iag.puc-rio.b

${ }^{2}$ Mestre em Adminitração pela IAG/PUC-RJ.Endereço: Rua Visconde da Silva, 33 Apto. 504 - Botafogo - Rio de Janeiro/RJ - Brasil - CEP: 22271090. Email: mzornoff@yahoo.com.br
}

Artigo submetido em setembro de 2007 e aceito outubro 2007 


\section{Introdução}

Aproximadamente três quartos das famílias brasileiras pertencem às classes $\mathrm{C}, \mathrm{D}$ e $\mathrm{E}$ (renda familiar mensal de 927,00 reais em 2000 [http_1] que, atualizada com base no salário mínimo, corresponderia em 2007 a 2.100,00 reais). Essas famílias respondem por $42 \%$ do consumo no país e movimentam, por ano, cerca de 390 bilhões de reais (BARRETO e BOCHI, 2002; BLECHER E TEIXEIRA JR., 2003).

Até o início da década de 1990, esses consumidores despertavam pouco interesse de varejistas e fabricantes (BARRETO e BOCHI, 2002), mas a abertura do mercado e a estabilidade econômica (a partir de 1994) mudaram esse cenário, tornando esses segmentos, atraentes, primeiro, para empresas locais de pequeno e médio porte e depois, para organizações globais como Coca-Cola, Unilever e Danone, tradicionalmente focadas, no Brasil, nas classes A e B (KAMIO, 2005).

Esse movimento em direção aos consumidores mais pobres dos países ditos "emergentes" não é um fenômeno exclusivamente brasileiro. "Até o final dos anos 80 , cerca de $75 \%$ das vendas dos fabricantes de bens de consumo, no mundo, provinham dos consumidores ricos e da classe média dos países desenvolvidos". Já na década passada, com os sinais de saturação desses mercados, os países emergentes ganharam relevância para as grandes empresas que estão em busca de resultados sustentáveis e crescentes (BLECHER e TEIXEIRA, 2003).

O livro de Prahalad, "A Riqueza na base da pirâmide: Como erradicar a pobreza com o lucro", publicado em 2004, pela Wharton School Publishing e lançado no Brasil, em 2005, pela Bookman, chamou atenção sobre a relevância desses mercados e também, sobre a necessidade abordá-los com uma visão inovadora:

"A base da pirâmide como mercado oferece uma nova oportunidade de crescimento para o setor privado e um fórum para inovações. Soluções velhas e desgastadas não podem criar mercados na base da pirâmide". (PRAHALAD, 2005, p. 19).

Como observam Prahalad e Lieberthal (2003), os consumidores de baixa renda dos países emergentes têm hábitos e padrões de consumo diferentes dos de classes mais abastadas (de países desenvolvidos e dos próprios países emergentes), o que significa que as empresas que desejam abordar esse mercado precisam repensar vários aspectos de seus modelos de negócios.

No Brasil, ainda se sabe muito pouco sobre esses consumidores que foram por décadas praticamente ignorados pelas pesquisas acadêmicas e de mercado. Se, no ambiente empresarial, essa realidade está agora dando sinais de mudança, no acadêmico, os estudos ainda são bastante escassos (MATTOS, M., 2007; BARROS, 2007). O objetivo deste artigo é efetuar uma revisão desses trabalhos, que têm caráter essencialmente descritivo/interpretativo, buscando avançar na interpretação de seus achados e, assim, contribuir para a construção de novas proposições de pesquisa.

\section{Orientação metodológica, estrutura e delimitações do estudo}

$\mathrm{O}$ interesse pelos consumidores de baixa renda é recente na literatura internacional e nacional. No Brasil, a maioria dos estudos acadêmicos realizados sobre esses consumidores tem caráter descritivo/interpretativo. $\mathrm{O}$ propósito deste trabalho é o de efetuar uma revisão desses estudos, buscando contribuir para o processo de interpretação de seus achados, com vistas ao aprofundamento e refinamento do conhecimento sobre consumidores brasileiros de baixa renda. Nesse sentido, ele se situa dentro de uma perspectiva interpretativa (BROWN, 1997; CASOTTI, 1999), onde, como assinala Geertz:

"os estudos constroem-se sobre outros estudos, não no sentido de que uns retomam onde outros deixaram, mas no sentido de que, mais bem informados e mais bem formulados quanto aos conceitos, eles mergulham mais profundamente, nas mesmas coisas" (GEERTZ, 1973, p. 35). 
A idéia é, portanto, a de procurar avançar nesse processo, tentando trazer uma contribuição para uma descrição mais densa das "estruturas significantes" (GEERTZ, 1973, p. 17 e 24) que organizam as atividades de consumo desses grupos de consumidores.

O artigo foi estruturado em torno dos temas recorrentes nos estudos revistos: o conceito de classe social e os debates existentes em torno dele; a gestão do orçamento entre consumidores de baixo poder aquisitivo; o modo como as pessoas que pertencem a esses grupos lidam com a experiência de fazer compras; e a questão do papel do preço e da marca nas suas decisões de compra.

A questão do conceito de classe social tem caráter mais teórico. Julgou-se que era, no entanto, importante abordá-la em razão de sua importância para o tema estudado, das discussões que ela suscita na literatura e em meios empresariais e, por estar presente em vários dos trabalhos examinados. Em seguida, são abordados os temas que dizem respeito ao comportamento propriamente dito dos consumidores "pobres" ou de baixa renda (as denominações variam de trabalho a trabalho).

Em razão das limitações existentes no país, em matéria de acesso a pesquisas, especialmente quando disponíveis somente sob a forma de dissertações ou teses, a pesquisa não pretende ser exaustiva. Foram privilegiados os trabalhos difundidos em veículos de maior difusão, como os anais EnANPAD (nesses levantaram-se todos os artigos que tinham por tema o comportamento dos consumidores de baixa renda publicados entre 2000 e 2006). Somente foram retidos os trabalhos que tratavam do comportamento dos consumidores; estudos que abordam estratégias empresariais no mercado de bens populares não fazem parte do escopo desse trabalho.

Os trabalhos examinados são heterogêneos nos seus objetivos, nas suas abordagens - embora todos tenham caráter qualitativo -, nos grupos de consumidores estudados e nos critérios de seleção desses grupos. Embora, como sublinham D'Andrea et. Al (2004), existam diferenças significativas - de renda, mas também de estilo de vida, atitudes e outras - entre os grupos que costumam ser designados pelos termos "consumidores emergentes" ou "populares", não foi possível aprofundar aqui esse aspecto. Dado o número reduzido de estudos aos quais se pôde ter acesso, optou-se por descrever designações e critérios de seleção utilizados em cada estudo e, eventualmente, utilizá-los na análise, sem entrar em comparações entre sub-grupos. É importante ressaltar, também, que os estudos encontrados se concentram nas populações urbanas do eixo São Paulo - Rio de Janeiro, as quais provavelmente tenham características distintas das de outras regiões e, mais ainda, de áreas rurais.

\section{Classe Social}

No Brasil, o critério utilizado por muitas empresas para a classificação econômica da população é o Critério de Classificação Econômica Brasil (CCEB). O CCEB utiliza características como a posse de bens, o nível de instrução do chefe de família e a existência de empregados(as) mensalistas no domicílio para estimar o poder de compra de famílias (domicílios). Ele divide a população em cinco classes (A, B, C, D e E), sendo duas subdividas em dois sub-grupos (A1, A2; B1, B2). Conforme posto pela ABEP (Associação Brasileira de Empresas de Pesquisa), esse critério foi construído para definir grandes classes que atendam às necessidades de segmentação da grande maioria das empresas. Ele não leva em consideração aspectos sociais e não tem a pretensão de fazê-lo (o site da ABEP inclusive afirma que o objetivo do critério é classificar indivíduos e famílias urbanas "por classes econômicas ao invés do pouco esclarecedor critério de classes sociais"). A estimativa do poder de compra é feita com base no LSE - Levantamento Socioeconômico, pesquisa anual do IBOPE Mídia, que mapeia as características sociais, demográficas e econômicas das famílias das 10 principais regiões metropolitanas do país: Grande São Paulo, Grande Rio de Janeiro, Grande Porto Alegre, Grande Florianópolis, Grande Curitiba, Grande Belo Horizonte, Distrito Federal, Grande Salvador, Grande Recife, Grande Fortaleza [http_1]. O princípio no qual o sistema se baseia é o de descobrir itens de conforto que tenham uma forte correlação com renda familiar, atribuir pontos (ou pesos) a esses itens e estabelecer pontos de corte de modo a dividir a população em estratos associados a diferentes níveis de poder aquisitivo (MATTAR, 1996). 
O critério foi, desde a sua criação, em 1970, objeto de vários debates, que envolveram diversas instituições (ABA -Associação Brasileira de Anunciantes, associações de institutos de pesquisa de mercado e outras), bem como profissionais de mercado e acadêmicos. Ele foi reformulado em 1996 [http_2] (MATTAR, 1996) e está sendo novamente discutido em 2007 (MATTOS, A. 2007). Um dos problemas que o CCEB e suas versões anteriores apresentam é que, como tomam por base a posse de bens de consumo, precisam ser periodicamente revistos à medida que os bens utilizados no sistema de pontuação se popularizam, perdendo seu caráter discriminatório, ou se tornam obsoletos em razão do surgimento de novas tecnologias (MATTAR, 1996). Esse problema não é somente pragmático. Ele remete às próprias estratégias das empresas, particularmente de tecnologia, onde o "desnatamento" - ou skimming - é comumente adotado (lançam-se inovações a preços elevados para, somente depois, reduzir os preços e atingir camadas de menor poder aquisitivo, MATTAR, 1996). Além disso, as pessoas, independentemente do estrato sócio-econômico ao qual pertencem, desejam cada vez mais certos bens, como TV a cores, automóvel e outros. Nesse sentido, utilizar a posse desses bens para discriminar grupos que, embora compartilhando desejos de consumo, diferem em renda e, possivelmente, em vários outros aspectos é um procedimento que deixa em aberto várias questões relativas às modalidades de consumo existentes entre esses grupos.

Embora haja um certo consenso em torno da idéia de que valores, motivações e processo de decisão de compra diferem de uma classe para outra, a natureza dessa relação ainda é um assunto pouco claro (COLEMAN, 1983; MATTOSO, 2005b). Primeiro porque envolve os próprios sistemas de divisão em classes das sociedades; segundo porque toca no papel e nos significados que o consumo assume dentro desses sistemas.

Ao efetuar uma revisão das abordagens do fenômeno "consumo", Barros $(2007$, p.32) as divide em duas categorias: as economicistas - que "reduzem o fenômeno do consumo à esfera do indivíduo visto como um ser racional, que realiza a compra a partir de uma escolha, em função da busca de maximização de sua utilidade" e as desenvolvidas no campo da Antropologia - que abordam o consumo como um fato social "refratário a explicações que o reduzam ao plano individual" e o vêem como um fenômeno eminentemente cultural e de natureza simbólica. Dentro dessa perspectiva, que tem sua origem nos trabalhos de Veblen e Mauss e nos estudos posteriores de autores como Mary Douglas, Marshall Sahlins, Pierre Bourdieu e Grant McCracken, o consumo é visto como um sistema simbólico, classificatório; e o pressuposto de que os indivíduos fazem suas escolhas de consumo de forma racional e "procurando sempre a melhor vantagem nas transações econômicas" é qualificado como "uma visão estreita da racionalidade humana" (BARROS, 2007, p. 41). Nesse sentido, pressupor a existência de uma relação constante e estável entre renda e consumo significaria ignorar as respostas diferentes que as culturas (e sub-culturas) desenvolvem para atender às suas necessidades (BARROS, 2007).

Essa perspectiva se insere na corrente "relativista/ interpretativa/"construcionista'/ humanística" que vem, desde a década de 1990, ganhando mais visibilidade na área de Comportamento do Consumidor (BROWN, 1997, p. 172). Como resumem Rocha e Barros (2004, p. 1), a idéia é que "o consumo só se resume a um fato econômico (...) até a fronteira do preço de entrada", necessário para adquirir bens e usufruir serviços. A partir daí, entram em jogo outros elementos mais complexos, de caráter simbólico; outras diferenças que não se resumem a níveis de renda ou à posse de determinados bens:

"O conhecimento efetivo do consumo, como um complexo sistema cultural da sociedade contemporânea, passa por entender as diferenças simbólicas que se inscrevem a partir da equalização dos pré-requisitos econômicos supostos na compra de qualquer bem". (ROCHA; BARROS, 2004, p.1).

Como se verá adiante, implícita ou explicitamente, essa abordagem é a que predomina nos estudos que são objeto dessa revisão, que buscam exatamente compreender as particularidades das atividades de consumo dos consumidores brasileiros de baixa renda e as realidades simbólicas em torno das quais elas se organizam.

É importante ressaltar, porém, que, como sublinha Geertz (1973, p. 40), a análise cultural não deve fazer perder de vista "as superfícies duras da vida", "as realidades 'estratificadoras' políticas e econômicas, dentro das quais os homens são reprimidos em todos os lugares". Essas realidades são particularmente prementes quando se fala em classes pobres dos países emergentes; e se a "lógica da falta" (BARROS, 2007, p. 6) não permite, por si só, 
dar conta da complexidade dos fenômenos de consumo nesses grupos, a escassez ainda é, como se verá, um elemento central para sua compreensão.

A seguir, é examinado um tema diretamente relacionado a essa questão, abordado por vários dos estudos aqui discutidos: o da gestão do orçamento familiar.

\section{A gestão do orçamento: entre necessidades e desejos}

O estudo de Mattoso (2005a) investigou, por meio de métodos qualitativos, as estratégias para solução de problemas financeiros dos pobres em moradores da favela da Rocinha, no Rio de Janeiro. Como ele aborda uma situação de crise - a de inadimplência ou necessidade não planejada de dinheiro - ele traz informações relevantes sobre a forma de administrar o orçamento doméstico.

Em primeiro lugar, a idéia de que o consumismo ou consumo compensatório poderia estar na origem de desequilíbrios financeiros não se confirmou. Os resultados apontam que os problemas financeiros dos pobres decorrem de eventos inesperados, como perda do emprego, doença, gravidez, morte de parente ou outros. Como há pouca ou nenhuma "sobra" no orçamento e, conseqüentemente, não existem reservas, tais acontecimentos acabam dando origem a uma "cadeia de causalidade perversa", que, por sua vez, leva à inadimplência (doença causa a perda do trabalho que era a fonte de renda; gravidez leva ao desemprego e ao aumento das despesas familiares, etc.). (MATTOSO, 2005a, MATTOSO e ROCHA, 2005).

As estratégias mais freqüentemente utilizadas para resolver problemas financeiros são: "não pagar" e "contrair empréstimos". Os relacionamentos, de trabalho (patrões) e pessoais (parentes e amigos), são costumeiramente mobilizados. A prática de "tomar emprestado" e "emprestar" o nome (abrir um crediário ou usar o cartão de crédito de outra pessoa para se fazer uma compra) é amplamente difundida, bem como o receio de "sujar o nome" (isto é, ter o nome incluído no SPC - Serviço de Proteção ao Crédito - entidade que cadastra devedores para auxiliar empresas de crédito, lojas, bancos e comércio em geral - [http_3]). (MATTOSO, 2005a ; MATTOSO e ROCHA, 2005).

Um aspecto interessante é que vários depoimentos sugerem que a quitação da dívida é vista, ou não, como prioritária em boa parte, de acordo com o nível de necessidade da pessoa ou entidade a quem se deve. Assim, patrões costumam não ser prioridade, pois "têm sobrando" e o dinheiro emprestado, supostamente, não lhes faz falta. Não pagar uma conta pode trazer problemas futuros, mas é algo que se faz com naturalidade, sem grandes dilemas morais (empresas também "têm sobrando" e "não precisam"). Inversamente, é dever ajudar quem está precisando. Assim é que se "empresta o nome" a amigos e parentes que precisam efetuar uma compra, mesmo correndo o risco de "sujar o nome". Ainda dentro dessa lógica, na hora de reembolsar um amigo ou parente, avalia-se quem "precisa mais", o credor ou o devedor (MATTOSO, 2005a ; MATTOSO e ROCHA, 2005).

Não se constatou, nos entrevistados, uma visão de curto prazo e busca de gratificação imediata que pudesse explicar o surgimento de problemas financeiros, embora a autora sublinhe que a compra de bens a prestação, amplamente difundida, obedeça, ao menos em parte, a essa lógica (a posse imediata tendo apelo maior que a poupança). A autora menciona o termo proposto por Brusky e Fortuna de "poupança invertida" para designar essa prática, que consiste em acumular bens e mercadorias ao invés de dinheiro (Bursky e Fortuna, 2002, apud Mattoso, 2005). Mas a questão é provavelmente mais complexa, como mostra o estudo de Barros (2007), que será comentado a seguir. O que é notável, em todo caso, é que o discurso dos entrevistados enfatiza a racionalidade na gestão de seus recursos. Como se verá adiante, esse traço é evidenciado, também, em outros estudos. Segundo Mattoso, o tom dos depoimentos é "realista" e muitos entrevistados mostram planejar, de forma concreta e racional, seu futuro (MATTOSO, 2005a ; MATTOSO e ROCHA, 2005).

O trabalho de Barros (2007), cuja abordagem é de "inspiração etnográfica" (a denominação se refere ao fato de o estudo não seguir estritamente a etnografia tradicional, que "prevê a imersão prolongada e contínua do pesquisador em determinado grupo social", e sim, adotar um procedimento mais curto, como vem sendo feito em estudos etnográficos na área de marketing) investigou um grupo especifico: o das empregadas domésticas. É importante ressaltar que essa categoria profissional ocupa, como sublinha a autora, um lugar particular dentro 
da organização social brasileira. Empregadas domésticas trabalham, e freqüentemente residem, em ambientes de classe mais alta. Elas circulam entre esses ambientes e suas comunidades de origem e são cotidianamente confrontadas com as diferenças existentes entre esses grupos (BARROS, 2007, p. 139-144).

Barros chama atenção sobre o tom de surpresa encontrado em pesquisas realizadas por empresas de consultoria diante dos "excessos" encontrados no universo de consumo das famílias de trabalhadores pobres. Seus resultados mostram a existência de uma certa "sede" de consumo, combinada com um nível bastante elevado de atenção às escolhas. Várias das entrevistadas, por exemplo, se declaram conscientes dos juros embutidos nas compras a prazo e se dizem atentas ao seu montante, mas o parcelamento é uma opção atraente e, muitas vezes, a única possível: "eu gostaria de comprar a vista, mas a vista, nunca dá. Eu acabo comprando a prestação". A autora resume os achados relativos a essa questão observando que "a poupança acaba sempre sendo 'desafiada' pelo grande desejo de consumo imediato". Cita, também, o comentário de uma informante a esse respeito: "a maioria dos brasileiros não poupa porque quer comprar muito" (BARROS, 2007, p. 171).

No discurso das entrevistadas, as despesas prioritárias são as contas de casa (gás, luz, telefone) e a alimentação. No entanto, Barros relata que a prática de não pagar as contas de luz é bastante difundida no bairro que estudou (Bairro da Posse, Nova Iguaçu, RJ) e que se faz até ironia a respeito: "as lá de casa [contas da Light não pagas] já dão pra fazer um catálogo" (p. 172). Os gastos com os filhos têm alto grau de prioridade, principalmente os de alimentação e educação. Algumas entrevistadas mencionam, também, entre os gastos prioritários, os de plano de saúde. A autora nota, porém, a importância dada a itens mais supérfluos, como o tratamento de cabelos, e relata o caso de uma senhora que deu de presente à neta uma ida ao "melhor cabeleireiro de Nova Iguaçu", onde gastou 90 reais para alisar o cabelo (BARROS, 2007).

Um ponto importante, na pesquisa de Barros, é o da religião: pessoas que se dizem "evangélicas" ou cristãs", isto é, que pertencem a igrejas de orientação protestante, mostram-se mais propensas a uma gestão racional de seus recursos. Vale transcrever um trecho de depoimento que ilustra bem esse aspecto:

"Arrumar a casa para mim é mais importante. Se é para pintar a casa, eu prefiro que pinte a casa e que não tenha dinheiro no banco.O dinheiro no banco dá muito pouco, os juros. Se é para ficar comprando roupa, sapato, lanche na rua, sabe, para isso, sou uma negação. Eu acho isso um desperdício”. (Lourdes, empregada doméstica, evangélica, moradora do bairro da Posse).

Segundo Barros, essa combinação de racionalidade e senso de responsabilidade individual raramente é encontrada nos depoimentos das entrevistadas não evangélicas. A autora cita, inclusive, o depoimento de uma informante que é, "até hoje", criticada pela filha por ter trocado a escola particular onde esta estudava por um CIEP de baixa qualidade em razão da compra de uma TV e de um rádio (BARROS, 2007).

Os resultados dos estudos de Mattoso (2005a) e Barros (2007) têm, em comum, o fato de evidenciar a existência de uma preocupação em torno da gestão do orçamento e de um discurso bastante impregnado de racionalidade, ainda que nem sempre esta seja predominante. Mostram também que há uma hierarquia de prioridades nos gastos. Nessa hierarquia, as despesas de alimentação ocupam um lugar essencial. De fato, de acordo com o BCG, os gastos com supermercado (alimentação, higiene e limpeza) representam 48\% dos gastos de uma família de classe C (BARRETO e BOCHI, 2002). Os estudos abordados a seguir tratam dessa categoria de gastos.

\section{Alimentação, limpeza e higiene: despesas prioritárias}

O trabalho de Mattos, M. (2007) investigou a compra de duas categorias de produtos - refrigerante e sabão em pó - por meio de dez entrevistas em profundidade realizadas com consumidoras das classes C e D. Seu foco foi o papel da marca no processo de decisão de compra (que será abordado adiante), mas ele traz também várias informações sobre a gestão do orçamento. A autora destaca a frase de uma das entrevistadas, que resume bem o dilema das decisões de alocação de gastos:

"Quando eu pego o salário do mês, eu fico entre a espada e a parede, porque é muito pouco e tudo o que envolve o salário do mês são coisas de grande prioridade." (Mattos, M., 2007, p. 79). 
Os resultados do estudo mostram que as compras "de casa" (alimentação e produtos de limpeza) têm alto nível de prioridade no orçamento familiar. As mulheres entrevistadas dividem as compras da casa em dois grupos: as compras mensais (ou quinzenais) e as compras semanais. A compra mensal (ou quinzenal) é, nos termos das mulheres entrevistadas, "do grosso". Nessa cesta entram os produtos que são comprados em maior quantidade, itens declarados como sendo mais essenciais e que podem ser estocados (arroz, feijão, óleo, farinha, açúcar, sal, leite, macarrão, café). A compra semanal (e, às vezes, diária) é formada por produtos que estragam com mais facilidade como carne, legumes, frutas, verduras, queijo, presunto, pão e por itens mais supérfluos, que entram na casa após a compra mensal "do grosso" ter sido concluída. A autora observa que, embora com outra nomenclatura, a pesquisa do BCG (BARRETO e BOCHI, 2002) também identificou esse tipo de classificação. Nela, os tipos de compras realizadas pela baixa renda são divididos em: compra de abastecimento, compra de reposição e compras esporádicas. (MATTOS, M., 2007).

O estudo de Assad e Arruda (2006) investigou, por meio de métodos qualitativos (entrevistas individuais e focus group), a dinâmica do processo de compra junto a consumidoras de classe D e E (renda inferior a 4 salários mínimos) num bairro da Grande São Paulo. Seu objetivo era o de entender as preferências dos consumidores com respeito a supermercados. Os resultados evidenciam a mesma distinção encontrada por Mattos (2007) entre compras mensais, mais volumosas, e compras diárias. As autoras definem as primeiras como "a realização da missão da provedora, da administradora do lar" e as segundas como "um misto de lazer e terapia", que representa um passeio, "uma forma agradável de passar o tempo" (p. 13).

Parente, Barki e Kato (2005) pesquisaram, também, por meio de técnicas qualitativas (observação, entrevistas em profundidade e focus group), as motivações para compras de varejo em um bairro pobre da periferia de São Paulo. O estudo teve por foco três supermercados e abordou consumidores que residiam num raio de 500 metros em torno desses estabelecimentos. Os resultados evidenciam a mesma divisão, observada por Mattos, M. (2007) e Assad e Arruda (2006), entre compras mensais e diárias. A compra mensal, "mais pesada" ocorre, segundo Parente, Barki e Kato (2005, p.7), "de modo planejado e utiliza informações coletadas sobre preços e estabelecimentos" durante as visitas diárias. As compras diárias ou de maior freqüência estão ligadas a rendimentos eventuais, como os obtidos por meio de "bicos", e também ao lazer.

O estudo de Motta e Casarin (2006), baseado em 18 entrevistas em profundidade com donas de casa de famílias com renda de até quatro salários mínimos, buscou identificar e descrever, nos depoimentos das entrevistadas, estratégias de compra e consumo de alimentos. Foram identificados três tipos de estratégias: "obter o suficiente"; "criar abundância" e "ser eficiente". Dentro de cada estratégia, são descritas diversas táticas, algumas relativas à distribuição dos gastos. São elas:

- Prioridade para produtos que saciam, como arroz, feijão e massas (estratégia de "obter o suficiente");

- Gerenciamento de estoques, que as donas de casa entrevistadas procuram manter baixos, para não estimular um consumo excessivo (estratégia de "ser eficiente").

Esse último aspecto é também registrado por Parente et al $(2005$, p. 8), que observam que, nas suas compras quotidianas, "as donas de casa procuram dosar seus gastos em produtos alimentícios, que, ao serem comprados em doses diárias, permitem uma maior racionalização do consumo e economia nos gastos".

\section{A experiência de comprar: prazer e frustrações}

Um aspecto observado em vários dos estudos já citados é o do prazer associado ao ato de se fazer compras. A possibilidade de poder ir ao supermercado e levar os produtos importantes aos olhos da mulher (dona de casa) e desejados pela família gera um sentimento positivo, prazeroso, de recompensa. Esse aspecto é mencionado em vários estudos:

"Eu adoro [fazer compras de supermercado]. O meu marido não gosta muito por causa da fila, mas eu nem ligo, eu levo tudo na esportiva. Ah, a gente já se estressa tanto durante a semana, né, no final de semana tem que relaxar." (depoimento de Cleide, 37 anos, classe C-Mattos, M. 2007, p. 95). 
"Sinto-me com liberdade, com poder. É uma terapia". (Parente et al, 2005, p. 8).

"Me sinto a Gisele Bündchen, me acho linda e maravilhosa, tendo o dinheiro no bolso e ter um supermercado eu me sinto poderosa. Eu, com dinheiro, me sinto bem poderosa". (Parente et al., 2005, p. 8).

"Me sinto linda, maravilhosa, com poder e realizada por fazer minha familia feliz". (Assad e Arruda, 2006, p. 13).

Esse aspecto é mencionado também no relatório do BCG (BARRETO e BOCHI, 2002) e por D'ANDREA et. al (2004), que observam que o momento da compra tem caráter lúdico e é, às vezes, visto como prazer, lazer e fonte de auto-satisfação.

Por outro lado, esses sentimentos positivos coexistem com a frustração de não se poder adquirir tudo que se gostaria:

"É chato quando você vai com o dinheirinho contadinho, que só pode comprar aquilo". (Branca, 36 anos-Classe C-Mattos, M., 2007, p. 95).

"Eu gosto de comprar, mas hoje, o assalariado, não dá para comprar o que ele gosta".(Barros, 2007, p. 170).

"A gente sente um vazio de querer e não poder comprar" (Parente et al, 2005)

"Se vou a um outro supermercado que tem mais variedade, me sinto mal porque não posso comprar tudo que quero". " (Parente et al, 2005)

"Eu adoro fazer compras (...). Eu me sinto o máximo, se eu pudesse, eu pegava um carrinho e enchia o carrinho de bastante coisa. Eu adoro fazer compra. E o que te deixa feliz quando você compra? Ah, eu fico feliz quando eu consigo comprar de tudo o que eu quero." (Francisca, 58 anos - Classe D Mattos, M., 2007, p. 95).

É importante observar que tais sentimentos ocorrem ao se fazer compras de supermercado e não dizem respeito, portanto, somente a desejos de consumo de bens de maior durabilidade e valor. Eles são condizentes com o que se viu anteriormente sobre a gestão do orçamento. Trata-se de conciliar desejos - os de quem compra e os da família - com as limitações de um orçamento restrito. Transparece, em vários depoimentos, um desejo de poder "esbanjar", que remete a um ponto observado por Barros (2007). Segundo autora, os dados que ela recolheu no Bairro da Posse no Rio de Janeiro contrastam com a parcimônia e a economia encontradas por outro pesquisador (Stillerman, 2004 apud Barros, 2007) no Chile:

"Encontramos aqui um universo em que se evidencia um grande desejo de participar dos beneficios da sociedade de consumo." (Barros, 2007, p. 171).

Como se verá adiante, isso tem implicações para o processo de decisão de compra, no qual prioridades econômicas têm de ser conciliadas com aspirações de pertencimento a um universo de consumo que não se restrinja ao básico e ao estritamente necessário.

\section{Preço versus Marca: consumidores atentos a preços e sensiveis a marcas}

A noção de valor percebido pelo cliente designa a diferença percebida entre o conjunto de benefícios obtidos com um determinado produto ou serviço e o custo total (monetário e não monetário) despendido em sua aquisição, incluindo-se, tanto nos benefícios quanto nos custos, todos os elementos considerados como relevantes pelo cliente (ZEITHAML, 1988; KOTLER, 2000; CHURCHILL JR.; PETER, 2003; VELUDO-DEOLIVEIRA e IKEDA, 2005). O senso comum poderia levar a pensar que, para consumidores de baixa renda, os custos financeiros ocupam um lugar de destaque entre esses elementos, tendo peso maior que outros aspectos menos tangíveis como os relacionados à marca e, especialmente, a marcas premium. Autores como 
Prahalad (2005) e D'Andrea, Stengel e Goebel-Krstelj (2004) questionam, porém, a idéia, bastante difundida, de que pessoas de baixa renda dão prioridade ao critério preço - em detrimento da marca - nas suas escolhas de compra. Os trabalhos que abordaram esse ponto em estudos realizados no Brasil são examinados a seguir. Para facilitar a apresentação, essa parte foi subdividida em duas: na primeira, focou-se o fator preço; na segunda, a questão do papel das marcas.

\section{Preço: consumidores pesquisadores}

Como se viu no item "Gestão do Orçamento", em vários dos estudos examinados (MATTOSO, 2005; MATTOS, 2007; BARROS, 2007; MOTTA E CASARIN, 2006), o discurso dos entrevistados enfatiza a questão da racionalidade na gestão do orçamento doméstico. Dentro dessa, surge, evidentemente, a questão da atenção dada pelos consumidores ao fator preço.

O estudo de Assad e Arruda (2006, p. 13) mostra que há, entre as entrevistadas, empenho em pesquisar preços, tarefa que pode ser realizada nas visitas diárias ao supermercado, durante as quais se pode verificar que estabelecimentos estão com os melhores preços e para que produtos. Segundo os autores, essas informações são usadas "como meios de controle e planejamento do orçamento".

O estudo de Kelman, Chauvel e Godinho (2005), baseado em três focus-groups com mulheres de classe C, procurou investigar a visão que essas consumidoras têm dos anúncios televisivos de supermercados, focando os chamados "filme varejão" (filmes publicitários com 30 segundos de duração, que dedicam a maior parte desse tempo à apresentação dos produtos e de seus preços).

Os resultados apontaram que as consumidoras têm grande interesse nesses filmes (entre os seis anúncios que lhes foram apresentados, esses foram os que mais despertaram sua atenção, exatamente por divulgarem os preços dos produtos). Mostraram, também, que as consumidoras consideram esses filmes uma forma prática e conveniente de conhecer as promoções e decidir em qual supermercado comprar antes de sair de casa. As entrevistadas mostraram que memorizavam as ofertas e utilizavam essa fonte de informação para comparar preços:

"Normalmente, as propagandas de supermercado têm horário para serem exibidas, e o horário mais forte é o das 20 horas...começa uma atrás da outra...aí sim você pode começar a comparar...se você ficar 20 minutos ali, você sabe o preço de todos os mercados!’. (KELMAN, CHAUVEL e GODINHO, 2005, p. 10).

Disseram levar em conta diferenças de centavos, bem como critérios como o volume da compra, a distância do supermercado, o custo de transporte e a qualidade do produto para escolher o local de suas compras.

$\mathrm{O}$ artigo desses três autores conclui que as consumidoras entrevistadas não acreditam em promessas genéricas de "preço baixo". Baseiam sua escolha nas ofertas efetivamente propostas. Nesse sentido, os "filmes varejão" exercem um papel importante, pois eles são utilizados para se decidir onde as compras serão feitas .

A pesquisa de Motta e Casarin (2006) mostra que uma das táticas utilizadas dentro da estratégia de "obter o suficiente" é a pesquisa de preços. Os autores dão a essa tática o nome de "compra meticulosa". Segundo eles, as donas de casa estudadas se comportam como verdadeiros "detetives de preços". Pesquisam promoções, estudam os folhetos de supermercados, memorizam os anúncios de televisão para escolher o supermercado onde irão fazer suas compras. Tomam sua decisão levando em consideração os custos de transporte. No supermercado, chegam a gastar três horas para efetuar suas compras, comparando preços, adicionando e retirando produtos do carrinho de compras para compor a melhor cesta possível, dado o orçamento de que dispõem.

Os resultados do trabalho de Parente, Barki e Kato (2005) apontam, também, que as consumidoras pesquisadas se consideram "experts" em preços e têm a sensação de "auferir o maior proveito possível de seu limitado orçamento" (p. 8); mas esse discurso, eminentemente racional, nem sempre se confirma nos fatos. Embora declarem que o preço é o primeiro fator que levam em consideração, as consumidoras são fortemente 
influenciadas pelo ambiente da loja e pelo atendimento e dão preferência ao estabelecimento que mais as satisfaz quanto a esses aspectos, em detrimento de lojas que praticam preços inferiores.

"A loja B, apesar de praticar preços 7 a 8\% mais altos que seus concorrentes, apresenta, na percepção dos consumidores, uma proposta de valor mais adequada, sendo até mesmo percebida como a loja com os melhores preços da região" (PARENTE, BARKI E KATO, 2005, p. 13).

\section{Marca: um meio de reduzir riscos, de se diferenciar e de receber um tratamento "diferenciado"}

Segundo Kotler (2000), uma marca é essencialmente uma promessa de fornecer uma série específica de atributos, benefícios e serviços uniformes para os compradores. A marca pode trazer, então, até seis níveis de significado: atributos, benefícios, valores, cultura, personalidade e usuário. Os significados mais permanentes de uma marca são seus valores, cultura e personalidade, pois eles definem a essência da marca. Para Aaker (1998), a marca é composta por ativos e passivos que podem ser agrupados em cinco categorias (ou dimensões): (1) lealdade à marca, (2) conhecimento da marca, (3) qualidade percebida, (4) associações à marca em acréscimo à qualidade percebida, e (5) outros ativos do proprietário da marca (patentes, trademarks, relações com canais de distribuição, etc.). Nesse processo de construção de valor de marca, as empresas lidam com elementos subjetivos. A qualidade percebida, por exemplo, pode ser definida como o conhecimento que o consumidor tem da qualidade geral ou superioridade de um produto ou serviço pretendido, em relação a outras alternativas. Ou seja, as percepções dos consumidores são determinantes (AAKER, 1998). Além disso, essas percepções envolvem não somente atributos intrínsecos (funcionais), como também atributos extrínsecos como, por exemplo, personalidade ou atitude (ARVIDSSON, 2005).

Tradicionalmente, dividem-se as marcas em duas grandes categorias. As marcas premium (ou A-brands) são marcas pertencentes a grandes empresas locais ou multinacionais, que constroem uma oferta de valor para $\mathrm{o}$ consumidor baseada em qualidade, diferenciação, e cobram, por isso, preços acima das marcas populares (BARRETO e BOCHI, 2002). São marcas que oferecem mais que valores intrínsecos para o consumidor; propõem promessas e experiências. As $B$-brands, também chamadas de marcas de preço ou marcas locais, são marcas que competem no mercado, através de um posicionamento de preço baixo e sem a "pretensão" de construir uma relação mais profunda e duradoura com o consumidor. Oferecem um pacote de valor (qualidade, serviço, variedade de portfólio) inferior ao das marcas premium. Giovinazzo (2003, p. 18) propõe que:

"pode-se considerar que as marcas de preço são as marcas populares, posicionadas, predominantemente, para as classes de renda $C, D$ e E e cujo efeito-renda é negativo, ou seja, um acréscimo na renda deverá ocasionar uma substituição desta marca, por uma marca não popular”.

A proliferação das B-brands no Brasil surgiu de um espaço deixado pelas grandes empresas que, durante algum tempo, entenderam que suas marcas premium tinham potencial de consumo apenas nas classes mais altas da população (classes A e B) (BARRETO e BOCHI, 2002).

A pesquisa de Motta e Casarin (2006) mostra que "comprar a marca certa" é uma das táticas utilizadas na estratégia de "ser eficiente". As donas de casa pesquisadas compram com freqüência marcas mais caras por serem as que agradam à família. Isso permite evitar desperdícios. Elas também acreditam que marcas mais baratas podem acabar custando mais caro (um açúcar de marca ruim não adoça, de modo que é preciso usar mais; um feijão de marca inferior demora mais para ser cozido, levando a um maior gasto de gás). Os autores sublinham que o risco de se fazer uma compra equivocada está claramente presente nas preocupações das entrevistadas e que a marca desconhecida e barata desperta muitas vezes suspeitas. Ao mesmo tempo em que buscam preços baixos, as consumidoras costumam se manter fiéis a algumas marcas nas quais depositam confiança (MOTTA e CASARIN, 2006).

O estudo de Mattos, M. (2007) investigou a compra de duas categorias de produtos - refrigerante e sabão em pó - em consumidoras das classes $\mathrm{C}$ e D. Seu foco foi o papel da marca no processo de decisão de compra. Baseado nos resultados de uma pesquisa conduzida pelo BCG (BARRETO e BOCHI, 2002) com os consumidores de classe $\mathrm{C}$ do Brasil, o trabalho parte da observação de que as duas categorias de produto 
ocupam lugares distintos na cesta de compras desses consumidores: o sabão em pó é considerado um produto imprescindível, enquanto o refrigerante é um item abandonado se o dinheiro disponível for limitado.

Os resultados evidenciam que a marca exerce papéis distintos nos dois tipos de compra: No caso de refrigerante, as mulheres entrevistadas avaliam, em geral, $\left(1^{\circ}\right)$ os refrigerantes não reprovados pela família, $\left(2^{\circ}\right)$ preço, $\left(3^{\circ}\right)$ orçamento disponível e $\left(4^{\circ}\right)$ marcas preferidas (premium). No caso de sabão em pó, a escolha parece ser feita levando-se em consideração $\left(1^{\circ}\right)$ marca (verbalizada como sendo a opção pela qualidade), $\left(2^{\circ}\right)$ preço e $\left(3^{\circ}\right)$ orçamento disponível. Avaliando os elementos subjetivos da compra e indo além do discurso das mulheres entrevistadas, a compra do refrigerante preferido pela família traz a recompensa pelo elogio dos filhos e marido; enquanto a compra do sabão em pó das marcas premium (percebida por elas como as marcas de melhor qualidade) traz um sentimento de realização do cuidado com a família, a certeza de ter feito a compra certa, mais inteligente, de melhor custo/benefício. A autora conclui que a equação de valor que rege a decisão de compra não é simples, nem única. Há modelos diferentes para a tomada de decisão de compra de produtos distintos, como refrigerante e sabão em pó (MATTOS, M., 2007).

Tanto no estudo de Mattos, M. (2007) quanto no de Motta e Casarin (2006), fica claro que a marca funciona como um meio de se reduzir o risco de fazer uma má compra. Conforme descrito pelas teorias de comportamento do consumidor, a marca é utilizada para simplificar o processo de tomada de decisão (SOLOMON, 2000, p. 224), e a preferência por marcas é um dos meios utilizados pelos consumidores para reduzir os riscos percebidos nas decisões de compra (KOTLER, 2000, p. 204). Há diferentes tipos de risco: monetário (perda financeira), funcional (produto não apresenta o desempenho esperado); físico (prejuízo na saúde); social (enfrentar o menosprezo de familiares, amigos ou conhecidos); psicológico (prejuízo na autoimagem) (SOLOMON, 2000, p. 217).

Um aspecto notável nas pesquisas aqui descritas é que a limitação do orçamento parece inibir experimentações, mesmo em se tratando de produtos cujo custo poderia ser visto como pouco elevado por pessoas que não pertencem a esses grupos. Outro ponto é que parte do risco percebido diz respeito à resposta da família. Esse critério, ao menos para algumas categorias de produtos, abre espaço para que B-brands possam conquistar a lealdade desses consumidores. Marcas experimentadas e aprovadas pela família entram na cesta de compras e acabam se tornando uma alternativa segura para a dona de casa que, como dizem Assad e Arruda (2006, p. 13), deseja se sair bem na sua missão de provedora e boa administradora do lar.

Por outro lado, experiências mal sucedidas despertam fortes sentimentos negativos. Motta e Casarin (2006) observam que os consumidores expressam indignação quando suas expectativas não se vêem confirmadas e se mostram, nesses casos, extremamente decepcionados (MOTTA e CASARIN, 2006). Kelman, Chauvel e Godinho (2005) descrevem que as consumidoras se sentem enganadas quando decidem fazer suas compras em determinado supermercado em razão das ofertas exibidas em anúncios varejão e percebem, ao chegar na loja, que a qualidade dos produtos vendidos é inferior à sugerida pela propaganda (KELMAN, CHAUVEL e GODINHO, 2005).

Sentimentos de forte decepção foram também descritos por Chauvel (2000a e 2000b), que pesquisou 33 consumidores insatisfeitos, de várias classes, por meio de entrevistas em profundidade e relata testemunhos indignados de informantes de classe $\mathrm{C}$ e $\mathrm{D}$ que haviam adquirido produtos cujo desempenho tinha ficado abaixo de suas expectativas. A autora observa que parece haver um estigma associado às marcas voltadas para um público mais popular e que, em contrapartida, se espera de uma marca conceituada que ofereça segurança na compra - isto é, que não falhe - além de um tratamento digno e respeitoso para com o cliente. Ela evoca o caráter hierarquizado da sociedade brasileira para explicar esse fenômeno e sublinha que, "ao adquirir uma marca conceituada, o consumidor espera ser tratado como alguém que tem uma posição social privilegiada, isto é, como um cliente que dispõe de um certo poder e cujos direitos (...) devem ser respeitados" (CHAUVEL, 2000b, p. 138). Segundo ela, a marca traz, nesse sentido, uma promessa, que, quando não é cumprida, desperta nos consumidores de classe mais baixa um grande ressentimento e a idéia de que são discriminados.

Os resultados de Assad e Arruda (2006) revelam, também, a presença de uma grande sensibilidade à discriminação. Embora não toquem na questão das marcas de produtos, eles abordam a imagem dos supermercados freqüentados pelas consumidoras e mostram que essas se sentem "indignadas e ofendidas" com 
a forma rústica com que se apresenta um dos estabelecimentos estudados. Os consumidores interpretam esse fato como uma opção da empresa: como se trata de um bairro pobre, não é preciso ter sofisticação; qualquer coisa pode ser colocada no acabamento da loja (piso, iluminação, etc.). Vale transcrever alguns trechos dos resultados obtidos no exercício de personalização do estabelecimento em questão:

"É homem rico, estrangeiro e não se mistura com a gente, não é do povo, é moço, meia idade, mais ou menos 50 anos, nada sofisticado, homem de poder, não é simpático, é educado, colaborador" (Focus group 1, p. 9).

"Um empresário, um homem frio, só pensa em dinheiro, faz discriminação social, não tem personalidade fixa, é um camaleão, não investe, tem o coração duro, sempre muda de funcionário" (Focus group 2, p. 11)

Nos dois grupos, as entrevistadas declaram, ainda assim, freqüentar a loja, mas elas dão preferência a outro estabelecimento, visto como "uma pessoa mais simples, do povão, gentil, alegre" (Focus group1), "com coração grande, coração de mãe, de bom humor" (Focus Group 2).

Da mesma forma, no estudo de Parente et al (2005, p. 11), os consumidores pesquisados criticam um dos estabelecimentos pesquisados por ser excessivamente despojado, com "chão rústico e aparência pobre", e interpretam esses elementos como uma sinalização de que a loja "foi feita para pobre", pois, na visão da empresa, o bairro "não merece uma loja melhor". Como se viu anteriormente, acabam dando preferência a outro estabelecimento, chegando inclusive a acreditar que esse oferece melhores preços, embora tal avaliação não corresponda à realidade.

O estudo de Barros (2007) mostra que a expectativa de um tratamento respeitoso orienta preferências por lojas como as Casas Bahia, que, além de facilidades para a concessão de crédito - a renda "oficial" não é um limitador estrito, como em outras redes de varejo - oferecem um atendimento dedicado, mostrando que "aceitam o mundo das entrevistadas" (p. 207).

"As casas Bahia pegam você na porta, eles se dedicam mesmo, abrem o coração, para laçar você ali na hora. Agora, o Ponto Frio, você é que tem que ir lá-êi, êi [como se estivesse tendo que chamar o vendedor]. Acho que as Casas Bahia têm mais dedicação à pessoa". (Barros, 2007, p. 207)

“As Casas Bahia são como uma mãe, facilita pra gente. É rápido tirar [comprar] as coisas lá”. (Barros, 2007, p. 207)

"Uma vez, eu fiquei até chateada com eles [Ponto Frio], (...) eu fui fazer o crediário lá com eles e aí eles disseram que carteira assinada em casa de família não é comprovante de renda. Aí eu até fiquei furiosa lá, falei que ia processar eles, que isso é discriminação". (Barros, 2007, p. 208).

Os resultados de Barros (2007) evidenciam, também, um grande conhecimento sobre marcas, em várias categorias de produtos, que vão de produtos de limpeza e alimentos a roupas e itens como telefones celulares. Barros relata um exemplo significativo sobre cervejas. A marca Skol aparece nos depoimentos de seus informantes como uma referência de marca de prestígio. A pergunta "vai ter Skol?" surge como resposta a um convite para uma festa, e uma resposta negativa é motivo de chacota, com ameaças de não comparecer. Outros informantes relatam sentimentos de vergonha ao serem flagrados num bar tomando marcas tidas como inferiores, como Nova Schin, Cintra, Lokau, Belco e Bavária. Um homem declara: "eu não sou homem de cerveja de 1,50 [Nova Schin] não; sou homem de cerveja de 2,20 [Skol]” (BARROS, 2007, p. 210).

Esse tipo de consumo conspícuo (VEBLEN, 1965, apud BARROS, 2007), no qual produtos e marcas são utilizados como instrumento de distinção, num sistema classificatório que estrutura divisões entre bens e grupos de pessoas, é mencionado pelos informantes relativamente a várias categorias de produtos. A autora registra o uso de um termo genérico para designar essa classificação: ser ou não "de marca". Na linguagem dos informantes, o termo designa categorias distintas, sem que seja necessariamente preciso esclarecer qual a marca. Ou seja, bens e produtos parecem ser divididos em duas grandes categorias: com ou sem marca. A autora sublinha ainda que, dentro da categoria "com marca" há itens "interditados", porque são de outras 
classes sociais e não podem ser adquiridos. Os pais podem ser pressionados pelos filhos para comprar produtos "de marca" e, eventualmente, incorrem num sacrifício para atender a tais pedidos (BARROS, 2007).

De modo geral, os resultados de pesquisa, acima descritos, tendem a confirmar a afirmação de Prahalad de que "os pobres são muito conscientes de marca" e "são também extremamente conscientes de valor, por necessidade" (PRAHALAD, 2005, p. 25). O risco percebido parece exercer um papel importante nas decisões de compra dos consumidores pesquisados: risco financeiro, cuja importância deriva da escassez de recursos, e risco social, associado aos significados da marca. A busca por preços baixos coexiste, assim, com uma forte consciência de marca e com aspirações a níveis de consumo mais elevados em termos quantitativos e qualitativos. Esses aspectos são condizentes com a noção de valor descrita no início deste item.

É importante notar, porém, algumas particularidades que parecem estar relacionadas ao contexto sócio-cultural brasileiro. Em primeiro lugar, o risco social parece ter duas "vertentes": uma pública, associada ao status, como no exemplo da cerveja, mencionado por Barros (2007); outra privada, associada à família que pode criticar ou reprovar as escolhas de compra. Está em jogo, no último caso, o papel de provedor assumido pela pessoa que efetua a compra, que precisa, ao mesmo tempo, poupar recursos e agradar aos diferentes membros da família (a estratégia de "criar abundância", descrita por Motta e Casarin, 2006, retrata bem esse dilema; trata-se, por exemplo, de arrumar o prato de forma a que pareça haver mais carne do que há). Esses dois aspectos remetem à distinção, descrita por DaMatta (1986, p. 27-29), entre o universo da "rua" (regido por leis anônimas, onde "não há, teoricamente, nem amor, nem consideração, nem respeito, nem amizade") e o da "casa" (espaço "amoroso onde a harmonia deve reinar sobre a confusão, a competição e a desordem"). Dentro dessa perspectiva, haveria marcas apropriadas para o consumo em um e outro universo. Marcas que permitem ser visto com respeito e até admiração no universo da rua - que podem estar associadas ao ato de "esbanjar", por exemplo, tomando no bar a cerveja mais cara - e marcas que asseguram reconhecimento e aprovação dentro de casa. O sistema classificatório de marcas seguiria ,portanto, uma hierarquia que pode ser descrita da seguinte forma:

\section{Marcas premium}

2. Marcas conhecidas e aprovadas pela família

3. Marcas desconhecidas

4. Marcas experimentadas e rejeitadas pela família.

Além disso, as marcas parecem ser, também, divididas entre marcas "amigáveis" e "não amigáveis" aos consumidores de baixa renda. Essa categorização parece poder aplicar-se tanto a marcas premium quanto a $B$ Brands e, exercer influência sobre as percepções de valor e personalidade da marca. Marcas premium podem ser vistas como arrogantes e discriminadoras (como se viu no caso do supermercado descrito por Assad e Arruda, 2006 e no comentário sobre a loja Ponto Frio descrito por Barros, 2007). B-brands podem ser consideradas como marcas que "menosprezam" e "exploram" o consumidor de baixa renda, oferecendo-lhe produtos e serviços de qualidade inferior (como se viu nos resultados de Assad e Arruda, 2007 e Parente et al., 2005). Chauvel, 2000b, p. 134, relata, também, o exemplo significativo de uma marca popular de eletrodomésticos apelidada, numa interpretação jocosa de sua sigla, de "Errou Quando Comprou". Tal distinção deve ser compreendida dentro da perspectiva de uma sociedade ainda fortemente hierarquizada (DAMATTA, 1983 e 1986), onde a expectativa de desigualdade exerce forte influência sobre os julgamentos das pessoas e onde o respeito e a consideração são vistos como "benefícios" reservados às camadas superiores da sociedade. 


\section{Considerações Finais}

Buscou-se, neste artigo, discutir, dentro de uma perspectiva interpretativa, os achados de pesquisas recentemente feitas no Brasil sobre consumidores de baixa renda. A seguir, são apresentados alguns elementos interpretativos, retirados da análise dos estudos examinados. Procurou-se, também, elaborar uma proposta de articulação desses elementos.

Os resultados das pesquisas apresentadas no artigo apontam que a escassez de recursos é um dos eixos em torno dos quais se organizam a gestão do orçamento e as escolhas de compra e consumo. Os consumidores pesquisados dedicam muita atenção e tempo às decisões de alocação de recursos, hierarquizam seus gastos em ordem de prioridade, pesquisam preços e procuram organizar compras e consumo de forma a evitar desperdícios e retirar o máximo possível de seu orçamento. A idéia, oriunda da economia, de que os indivíduos realizam suas compras em função da busca de maximização de sua utilidade vê-se ilustrada nesses comportamentos. No discurso dos consumidores, essa dimensão racional é bastante enfatizada.

Isso não significa, porém, que a racionalidade econômica seja de fato sempre predominante nas escolhas de consumo. O que parece haver é uma preocupação com ela, um investimento de tempo, pesquisa, reflexão, um esforço voltado nessa direção, o que é muito compreensível, dadas as limitações financeiras, enfrentadas por esses consumidores.

A necessidade de economizar recursos coexiste, por outro lado, com desejos de níveis de consumo mais elevados, em termos de quantidade, qualidade e status associado aos bens consumidos. Observa-se, nos resultados de várias das pesquisas examinadas, uma vontade de consumir mais e melhor, bem como, de prazer em fazer compras, mesmo rotineiras como as de supermercado, e até mesmo, de desejos de "esbanjar". Essas aspirações se chocam com a escassez de meios financeiros, gerando uma tensão claramente expressa por vários informantes.

Uma forma de lidar com essa tensão consiste em reprimir os anseios de consumo, especialmente os de caráter hedônico. É o que parece ocorrer com as empregadas de religião protestante, entrevistadas por Barros (2007). A religião é possivelmente um importante mediador na forma de equacionar o dilema, desejos de consumo versus escassez, mas tudo indica que, se ela pode atuar como um moderador ou 'racionalizador' dos apetites de consumo, a abundância, a "mesa grande, farta" é como afirma DaMatta (1986) um valor bastante disseminado, não só nesse público como na sociedade brasileira, como um todo. É importante lembrar, também, como o faz DaMatta, que tal valor é fortemente ancorado no caráter relacional da cultura brasileira. A mesa farta "celebra as nossas relações mais que nossas individualidades" (DAMATTA, 1986, P. 62).

Uma outra forma de lidar com a necessidade de racionalizar os gastos consiste justamente em hierarquizá-los de acordo com as relações envolvidas. Assim dá-se prioridade às despesas relativas às relações mais relevantes, como no pagamento de contas e dívidas dos entrevistados da Rocinha,de Mattoso (2005). Prioriza-se também a família e especialmente os filhos.

De forma mais complexa, os benefícios são hierarquizados de acordo com o valor relacional da compra. Assim, benefícios intrínsecos, como o sabor de um refrigerante, permitem que marcas não premium entrem na cesta de compras, desde que o produto seja aprovado pela família (MATTOS, M. 2007). Já no universo da "rua", o status associado à marca se torna mais relevante, fazendo com que no bar, se escolha uma cerveja mais cara (BARROS, 2007).

Por fim, a dimensão relacional é também mobilizada para avaliar as próprias marcas. Marcas conceituadas têm, verdadeiramente, um "compromisso" com o cliente: não podem falhar, pois paga-se mais caro exatamente em razão da expectativa de uma performance superior. Por outro lado, marcas podem ter um comportamento "antipático", uma postura de superioridade, que desperta rejeição. Podem também ser displicentes com consumidores de baixa renda, transmitindo desprezo e a impressão de que "exploram" os menos privilegiados. Tais avaliações parecem estar relacionadas ao receio de ser discriminado, tratado como um cliente de categoria “inferior" (CHAUVEL, 2000a e 2000b; ASSAD e ARRUDA, 2006; PARENTE et al, 2005). Aspectos 
intangíveis, como a qualidade do atendimento, têm, nesse sentido, um papel importante, pois são uma manifestação da postura da empresa: amigável e isenta de preconceitos ou arrogante e interesseira.

De modo geral, duas racionalidades parecem, assim, coexistir na formação das decisões de consumo: uma, "dura", material, derivada da escassez de recursos, que impõe sua economia e uma racionalização estrita dos gastos; outra, de ordem simbólica, ancorada em elementos culturais e particularmente, nas dimensões relacionais e hierárquicas da sociedade brasileira, bem como em instituições de forte significado nessa sociedade, como a família e a religião. 


\section{Referências Bibliográficas}

AAKER, D. A. Marcas - Brand Equity: Gerenciando o Valor das Marcas. São Paulo: Negócio Editora, 1998.

ASSAD, M. M.; ARRUDA, M. C. C. Consumidor de Baixa Renda: o Modelo de Dinâmica do Processo de Compra. In: XXX ENANPAD, 2006, Salvador. Anais... Salvador: ANPAD, 2006. 1 CD-ROM.

ARVIDSSON, Adam. Brand Value. Journal of Brand Management, Vol. 13, n. 3, p. 188-192, February ,2006.

BARRETO, F. e BOCHI, R. Mercados Pouco Explorados: Descobrindo a Classe C. The Boston Consulting Group, 2002. Disponivel em http://www.estacio.br/graduacao/marketing

/artigos/Explorando\%20a\%20Classe\%20C\%20no\%20Brasil\%20-\%20BCG\%202002.pdf. Acesso em 23/04/2007.

BARROS, C. Marketing e Etnografia: um Levantamento em Journals dos Anos 80 e 90. In: XXVI ENANPAD, 2002. Anais... Salvador: ANPAD, 2002. 1 CD-ROM.

BARROS, C. F. P. Trocas, Hierarquia e Mediação: as Dimensões Culturais do Consumo em um Grupo de Empregadas Domésticas. Rio de Janeiro: COPPEAD/UFRJ, 2007. Apresentada como Tese de Doutorado, UFRJ.

BLECHER, N.; TEIXEIRA JR. S. 0 discreto charme da baixa renda. Exame, São Paulo: Ed. Abril, n. 20, p. 36-48, 2003.

BROWN, S. Marketing Science in a postmodern world: introduction to the special issue. European Journal of Marketing, vol. 31, no. 3/4, p. 167-182, 1997.

CASOTI, L. O que é a Pesquisa do Consumidor? Reflexões Geradas a Partir de um Problema Prático. In: XXIII ENANPAD, 1999, Foz do Iguaçu. Anais... Foz do Iguaçu: ANPAD, 1999. 1 CD-ROM.

Como Enxergar Diferenças no Comportamento do Consumidor? Algumas reflexões Sobre os Caminhos do Marketing. In: I EMA - Encontro de Marketing da ANPAD, 2004, Porto Alegre. Anais... Porto Alegre: ANPAD, 2004. 1 CD-ROM.

CHAUVEL, M.A. Insatisfação e Queixa à Empresa: Investigando os Relatos dos Consumidores. In: XXIV ENANPAD, 2000a, Florianópolis. Anais... Florianópolis: ANPAD, 2000. 1 CD-ROM.

CHAUVEL, M.A. Consumidores Insatisfeitos: Uma Oportunidade para as Empresas. Rio de Janeiro: Mauad, $2000 \mathrm{~b}$.

CHURCHILL JR., G. A.; PETER, J. P. Marketing - criando valor para os clientes. 2. ed. São Paulo: Saraiva, 2003.

COLEMAN, R. P. The Continuing Significance of Social Class to Marketing. Journal of Consumer Research, Vol. 10, p. 265-280, Dec. 1983.

DAMATTA, R. Carnavais, Malandros e Heróis, 4a. Ed., Rio de Janeiro: Zahar, 1983

DAMATA, R. 0 que faz o Brasil, Brasil? 2a. Ed. Rio de Janeiro: Rocco, 1986.

D'ANDREA, G.; STENGEL, E. A.; GOEBEL-KRSTEL, A.. 6 Truths about emerging-market consumers: Booz Allen Hamilton pan-latin study of offline consumers gives insight into culture. 2004. Disponivel em: http://www.imakenews.com/ephilanthropy/e_article00024

0937.cfm. Acesso em 24/11/06.

GEERTZ, C. A Interpretação das Culturas. Rio de Janeiro: Zahar, 1973.

GIOVINAZZO, Renata A.; WRIGHT, J. T. C.. Um estudo sobre o desempenho e a estratégia das empresas que atuam no mercado de bens populares no Brasil. VII SEMEAD. São Paulo, 2003.

KAMIO, G. Sob Medida para a Baixa Renda. Exame, São Paulo: Ed. Abril, Junho de 2005. KELMAN, J.C.; CHAUVEL, M. A.; LOPES, R. G. How to Communicate with Low Income Consumers: a Qualitative Study on Supermarkets Ads. In: DICOEN - III Conference on Discourse, Communication and the Enterprise, 2005, Rio de Janeiro. Anais... Rio de Janeiro: DICOEN, 2005. 1 CD-ROM.

KOTLER, P. Administração de Marketing: a edição do novo milênio. São Paulo: Prentice Hall, 2000.

MATTAR, F. N. Porque os Métodos de Classificação Socioeconômicos Utilizados no Brasil não funcionam. In: XX ENANPAD, 1996, Angra dos Reis. Anais... Angra dos Reis: ANPAD, 1996. Disponivel em: http://fauze.com.br . Acesso em 23/04/2007. 
MATTOS, M. P. A. Z. 0 consumidor de baixa renda e sua relação com as marcas no processo de decisão de compra de refrigerante e sabão em pó. Rio de Janeiro: IAG-PUC/RIO, 2007. Apresentada como dissertação de mestrado, PUC/RIO.

MATTOS, A. Institutos vão mudar definição de classe social. Folha de S. Paulo, 7 de janeiro de 2007. Disponível em: http://www.ibope.com.br. Acesso em 20/03/2007.

MATTOSO, C. 0. M.. Identidade, Inserção Social e Acesso a Serviços Financeiros: um Estudo na Favela da Rocinha. Rio de Janeiro: COPPEAD/UFRJ, 2005a. Apresentada como Tese de Doutorado, UFRJ.

Classes Sociais Uma Discussão sobre os Conceitos na Sociologia e Sua Incorporação ao Marketing. In: XXIX ENANPAD, 2005b, Brasilia. Anais... Brasilia: ANPAD, 2005. 1 CD-ROM.

MATTOSO, C. 0. M.; ROCHA, A. Significados Associados às Estratégias para Solução de Problemas Financeiros dos Consumidores Pobres. In: XXIX ENANPAD, 2005, Brasília. Anais... Brasilia: ANPAD, 2005. 1 CD-ROM.

MOTTA, P. C.; CASARIN, T. How Low-Income Consumers Increase the Amount of Food to Share with More. In: 6th Global Conference on Business \&t Economics, 2006, Boston. Anais... Boston: Harvard University, October 2006. 1 CD-ROM.

PARENTE, J. C.; BARKI, E.E. R.; KATO, H. T. Consumidor de Baixa Renda: Desvendando as Motivações no Varejo de Alimentos. In: XXIX ENANPAD, 2005, Brasilia. Anais... Brasília: ANPAD, 2005. 1 CD-ROM.

PRAHALAD, C. K. A Riqueza na base da pirâmide: Como erradicar a pobreza com o lucro. Porto Alegre: Bookman, 2005.

PRAHALAD, C. K.; LIEBERTHAL, K. The End of Corporate Imperialism. Harvard Business Review, Vol. 81, Issue 8, p. 109-117, Aug. 2003.

ROCHA, E.; BARROS, C.F. Dimensões Culturais do Marketing: Teoria Antropológica, Estudos Etnográficos e Comportamento do Consumidor. In: XXVIII ENANPAD, 2004, Curitiba. Anais... Curitiba: ANPAD, 2004. 1 CD-ROM.

ROSSI, C. A.; HOR-MEYLL, L. F. Explorando Novas Trilhas na Pesquisa do Consumidor. In: XXIX ENANPAD, 2001, Campinas. Anais... Campinas: ANPAD, 2001. 1 CD-ROM.

SOLOMON, Michael R.. 0 comportamento do consumidor: comprando, possuindo e sendo. 5a. Ed. Porto Alegre: Bookman, 2002.

VELUDO-DE-OLIVEIRA, T.M.; IKEDA, A. A. 0 conceito de valor para o cliente: definições e implicações gerenciais em marketing. Gestão.Org

- Revista Eletrônica de Gestão Organizacional. Recife, v. 3, n. 1, 2005. Disponível em: <http://www.gestaoorg.dca.ufpe.br/2/GESTORG_2005_N1_V3_ARTIGO_04.pdf>. Acesso em: 13 dez. 2006.

ZEITHAML, V. Consumer perceptions of price, quality, and value: a means-end model and synthesis of evidence. Journal of Marketing, Chicago, v. 52, p. 2-22, 1988.

Sites consultados:

[http_1] http://www.abep.org/codigosguias/ABEP_CCEB.pdf - acessado em 02/01/2007.

[http_2] http://www.targetmark.com.br/janela.asp?id=51 - acessado em 20/03/2007.

[http_3] http://www.linkgratis.com.br/spc-serasa - acesso em 25/04/2007 